\title{
A representação orgânica no condomínio por planos
}

\author{
Paulo Carneiro Maia \\ Docente livre de Direito Civil da Faculdade \\ de Direito da Universidade de São Paulo.
}

1. O condomínio ${ }^{1}$ designado por planos, pela fecundidade do assunto, tem suscitado inúmeras e variadas questões. Muitas delas versadas pelos escritores, por vêzes insatisfatòriamente, enquanto outras persistem íntegras desafiando a intranquilidade dos estudiosos.

$\mathrm{Na}$ gama multifária dêsses temas avulta o da representação, como órgão coletivo, que não pode ficar insensivel à realidade subjacente.

2. A qualificação da natureza das pessoas jurídicas sempre dividiu e continua dividindo os escritores. Averigüa-se a cada passo. Bem por isto, a extensão do conceito de personalidade jurídica a entidades coletivas, embora

1. Os vocábulos condomínio, comunhão ou compropriedade, conquanto apresentem nuanças desiguais, não tendo nossa língua "nome breve" e extreme de dúvidas para revelar o conteúdo conceitual da comunhão em edifícios de apartamentos, por andares ou não, (PoNTes DE Miranda, Tratado de direito predial, 1947, Rio de Janeiro, José Konfino, vol. II, p. 27 n. ${ }^{\circ} 3$ e p. 29, n. ${ }^{\circ}$; J. A. DE FARIA Mota, Condominio e visinhança, 1942, São Paulo, Saraiva \& Cia., n. ${ }^{\circ}$ 8, p. 17; WrLson DE Souza CAMpos BATAlHa, Loteamentos e Condominios, 1953, São Paulo, Max Limonad, vol. II, n. ${ }^{\circ}$ 170, pp. 69/75), são empregados como sinônimos, generalizando-se o acolhimento dessa prática (EduARDo EsPINola, Posse. Propriedade. Compropriedade ou condominio. Direitos autorais, 1956, Rio de Janeiro, Conquista, n. ${ }^{\circ} 178-\mathrm{A}$, p. 334, nota 2; ORlando Ribetro de CAStro, A propriedade dos apartamentos, 1944, Rio de Janeiro, Rodrigues \& Cia., n. ${ }^{\circ} \mathrm{XV}$; pp. 50/51). 
não se espinhe das dificuldades que afrontem seu caráter unitário, reclama ordenação de idéias.

Regista o professor Vicente Ráo, depois de passar em análise os principais sistemas doutrinários destinados a qualificar a natureza das pessoas jurídicas, que no estádio atual do direito às propensões de elasticidade não são escassas. Suas palavras conclusivas foram as de que, efetivamente, se acentua, "no direito moderno, a tendência de se ampliar o campo de aplicação do conceito de personalidade jurídica de modo a compreender, por exemplo, os patrimônios separados, o condomínio, a massa hereditária e situações outras que, como estas, reclamam nova e melhor disciplina. Assim se procedendo, admitir-se-iam, ao lado de unidades jurídico-sociais, unidades meramente técnicas e jurídicas, dotadas, umas e outras, de subjetividade de direito" 2 .

3. A concepção romana da propriedade individualista, adotando a regra da indivisibilidade dos prédios por

Embora sem justificativa histórica, alguns escritores já estão perfilhando a expressão "propriedade horizontal", mais suscinta, para significar essa espécie de propriedade por planos (LUIZ DA CUNHA GONÇALVES, Tratado de direito civil, 1936, Coimbra, Coimbra Editora Limitada, vol. $\mathrm{XI}, \mathrm{n} .{ }^{\circ} 1.669$, p. 283 e Da propriedade horizontal por andares, 1956, Lisboa, Ática Limitada, n. ${ }^{\circ}$ 5, pp. 18/23; José Candido Pimentel Duarte, Edificio de apartamentos, 1935, Rio de Janeiro, Tip. Jornal do Comércio, n. ${ }^{\circ}$ 1, p. 11; Miguer Maria DE SERPA LoPes, Propriedade em planos horizontais. Edifícios de apartamentos, in Rev. de Direito 139/15-27 e Tratado dos registros públicos, 2. ${ }^{\mathrm{a}}$ ed., Rio de Janeiro, Editora A Noite, vol. IV. n.os 676-690, pp. 253/297; ORLANDo GOMEs, Direitos reais, 1958, Rio de Janeiro, Companhia Editora Forense, n. ${ }^{\circ} 173$, pp. 301/302), a despeito de não ser ela isenta de mácula, implicar na existência oposta de propriedade vertical, quando tôda propriedade tem extensão horizontal e vertical, e poder constituir até um paradoxo das construções que se levantam em sentido chamado vertical.

2. O direito e a vida dos direitos, 1958, Max Limonad, São Paulo, vol. 2, n. ${ }^{\circ} 124$, p. 250 . Sem que o condomínio seja, pròpriamente, pessoa jurídica, ente dotado de personalidade, encerra comunidade de interêsses, tanto ativos como passivos, no qual, por vêzes, há comportamento assemelhado a aconselhar que se credencie, com atribuições, quem por êle possa agir, em nome do grupo, no mundo exterior. 
planos ${ }^{3}$, cedeu lugar ao critério oposto, qual o da sua divisibilidade em unidades autônomas.

Com a codificação francesa, seguida de perto pelas que nela se moldaram ${ }^{4}$, regulando a matéria para épocas que já se foram e sem lhe dar maior projeção, desbordou o problema para as leis especiais.

Entre nós, como interessa lembrar, ante as contingências impostas pelas construções modernas fraccionadas, que os rumos sociais e as conveniências econômicas alvitraram, cogitou o Congresso Nacional de regular o assunto. Fê-lo, há mais de trinta anos, através de diploma legislativo que dispôs sôbre a alienação parcial dos edifícios acima de cinco andares ${ }^{5}$.

Apesar de suas deficiências inegáveis e mesmo de seus defeitos de técniea - tudo a exigir novas vistas do legislador pátrio - êsse decreto visou a atender àquelas necessi-

3. A asseveração de SAvignY quanto à repetida repulsa do direito romano pela compropriedade dos andares não é mais tranqüila a teor dos reparos de Filaderfo Azevedo, (Destinação do imovel, 1932, Rio de Janeiro, Tipografia Alba, n. ${ }^{\circ}$ 27, p. 118), LuIz Machado GuIMARÃES, (Comentários ao código de processo civil, 1942, Rio de Janeiro, Edição Revista Forense, vol. IV, n. ${ }^{\circ} 87$, p. 88, nota 137), MIGUEL MARIA DE SERPA LOPES, cit. (Tratado dos registros públicos vol. IV, n. 679, p. 266), Pontes DE Miranda, (op. vol. cit., vol. II, $\S 7$, p. 31) e notadamente de Stanislau Pineles, (Questions de droit romain, tradução de Nicolas Herzen, 1911, Paris, V. Giard \& E. Brière, pp. 13/32), pelo primeiro divulgado entre nós e que, no seu dizer, demonstrou, "com argumentos de erudição pouco vulgar", a tese oposta bem como o "uso imemorial dêsse sistema de habitação, salvo na Germânia".

4. C. c. francês, art. 664, com a redação da lei de 28.VI.1938, e modificações do dec. de 29.XI.1939, e da lei de 4.II.1943; c. c. italiano de 1865 , arts. 562 e 564, sendo essa matéria hoje tratada, de modo sistetematizado, pelo c. c. de 1942, em capítulo próprio, arts. 1.117 a 1.139; c.c. espanhol, art. 396 , com a redação da lei de 26.10 .1939 e outros códigos mais.

5. Dec. 5.481, de 25.6.1928. O art. 1 dêste decreto foi modificado, originàriamente, pelo dec.-lei 5.234, de 8.2.1943, depois pela lei 285, de 5.6.1948, reduzindo-se a exigência, primeiro, de cinco para três andares, depois de três para "dois ou mais pavimentos" a fim de ser instituído condomínio em qualquer edifício. 
dades geradas por outras condições de vida, nas cidades maiores, com suas abrangências múltiplas.

4. Pela sistemática do decreto regulador dessa espécie de condomínio ficaram distinguidas, como convinha, a unidade autônoma, com os direitos e obrigações que lhe são inerentes, e as partes comuns que constituem coisa inalienável e indivisível, pro partibus indivisis, do domínio de todos os proprietários do prédio (arts. 1 e 2).

Surgem aí, paralelamente, as obrigações propter rem ou $o b$ rem, que configuram direitos mixtos e constituem tertium genus a qualificar figuras ambíguas, que participam tanto do direito real como do direito obrigacional, tutelando relações em conflito dos jura vicinitatis ${ }^{6}$.

Estabeleceu-se critério para a administração do imóvèl, "no que respeita aos serviços que interessam a todos os moradores" (art. 8), às "despesas comuns de conservação do edifício" (art. 9) e às "obras que interessarem à estrutura integral do edifício ou seu serviço comum" (art. 10).

Ao lado das atribuições cometidas ao administrador, que, por costume, veio a ser denominado sindico ${ }^{7}$, escolhido pela forma preconizada (art. 8), estatuiu-se acêrca

6. Carlos Maximiliano, Condomínio. Terras, apartamentos e andares perante o direito, 1944, Rio de Janeiro, São Paulo, Livraria Editora Freitas Bastos, n. ${ }^{\circ}$ 54, p. 72; FILADELFo AzEVEDo, op. cit. n. ${ }^{\circ}$ 7, p. 30 e n. ${ }^{\circ}$ 28, p. 122; ALFREDo BuZAID, Da ação renovatória, 1957, São Paulo, Saraiva S. A., n. ${ }^{\circ}$ 96, pp. 158/159; LUIZ DA CUNHA Gonçalves, cit. Da propriedade horizontal ou por andares, p. 93; FRANCESCo FERRARA, Trattato di diritto civile italiano, 1921, Roma, Athenaeum vol. 1, único, n. ${ }^{\circ}$ 96, p. 451; Domenico Riccardo PERETTI-GRIVA, Il condominio di case, Torino, 1942, Utet, n. ${ }^{\circ} 6$, p. 57; HASSEN ABERKANE, Essai d'une théorie générale de l'obligation "propter rem" en droit positif français, 1957, Paris, Librairie générale de droit et de jurisprudence. n.os 21-29, pp. 18/26.

7. Censura Pontes DE MIRANDA o emprêgo do vocábulo escrevendo que "síndico é italianismo, que não corresponde à figura do administrador segundo a lei brasileira, nem há, no Brasil, sindicato de comuneiros. Ao nosso individualismo repugna êsses enxertos corporativos, com que escritores nossos, copiando livros estrangeiros, conspur- 
do orçamento, para atender às despesas comuns de conservação, e de seus efeitos vinculativos, inclusive quanto aos ausentes e dissidentes (art. 10).

Ésse quadro, nos seus contornos largos, já nos permite devassar e situar o motivo objetivado, qual o da representação condominial e sua órbita.

5. Semelhante idéia de indivisão segundo a qual, de um lado, o comuneiro é proprietário individual de sua unidade autônoma, com a propriedade plena e privativa que lhe é inerente, de outro lado, é titular de quota-parte ideal, inalienável $\mathrm{e}$ indivisível do domínio de todos os outros co-proprietários, sôbre o "terreno em que assentam o edifício e suas instalações e a que lhe sirva a qualquer dependência de fim proveitoso e uso comum" (art. 2), conduz à concepção de certa representação do órgão, considerado distintamente dos co-interessados na comunhão.

Já que o próprio diploma específico dispôs que o condomínio por meação de paredes, soalhos e tetos dos apartamentos "regular-se-á pelo disposto no código civil, no que lhe fôr aplicável" (art. 4), apegando-se a essa estrutura que "não repugnava a construção jurídica da comunhão pro diviso, com a porção maior dividida e' a porção menor indivisa" 8 , bem como preceituou quanto a administração (art. 8), verifiquemos as relações entre comuneiros nos dois graus de incidência. Façamo-lo atentos a que a administração, por sua natureza, envolve a representação nas controvérsias atinentes ao seu âmbito, a caracterizar aquelas "unidades meramente técnicas e jurídicas", dotadas de "subjetividade de direito", de que fala Vicente Ráo ${ }^{9}$

cam o nosso direito. Já é tempo de pensarmos por conta própria, ou melhor, de voltarmos a pensar por conta própria, bebendo a ciência. note-se a ciência, onde quer que a encontremos. $\mathrm{E}$ fazermos mais do que os outros", (Op. vol. cits., § 96, p. 238).

8. Pontes de Miranda, op. vol. cits., $\S 8, n .0^{\circ}$ 2, p. 32 . Tal não é a opinião de FILADELFo DE AZEVEDo, (op. cit., n. ${ }^{\circ}$ 27, 121), que, sem maior desenvolvimento, asseverou ter o nosso código silenciado a respeito.

9. Op. vol. loc. cits.. 
6. No condomínio tradicional - fazendo-se aqui abstração das teorias de sua natureza jurídica, a cujo balanço LoDovico Barassi procedeu a contento ${ }^{10}$ - encontramos elementos abonadores da construção representativa no condomínio por planos ou, pelo menos, aspectos análogicos que contribuem a tanto.

Com efeito, o condômino que, no interêsse da coletividade dos membros partícipes do condomínio, intenta qualquer medida judicial, age não sòmente em nome próprio, representando sua fração no imóvel, como em nome de todos. E até considerado por muitos um verdadeiro negotiorum gestor pelas dívidas contraídas em proveito da comunhão.

Tal situação jurídica - já o esboçamos em estudo de outra ordem ${ }^{11}$ - foi entrevistada, de há dilatado periodo a esta parte, pela doutrina dos povos cultos e se consubstancia no nosso direito positivo. Èste, de forma expressa, assegura a cada condômino, exercer "todos os direitos compatíveis com a indivisão" 12 .

Qualquer condômino pode intentar ação de nunciação de obra nova e defender, em geral, seus direitos no condomínio ${ }^{13}$.

Em diversas passagens processuais ${ }^{14} \mathrm{o}$ legislador tornou inconteste a atuação do condômino depois de firmar a regra do litisconsórcio unitário, havendo coincidência de direito objetivo ${ }^{15}$.

O princípio da representação recíproca assenta no dever de solidariedade já que não se compreende que o co-li-

10. Proprietá e comproprietá, 1951, Milano, Dott. A. Giuffrè, n.os 39-50, pp. 104/157.

11. Sôbre a individuaçẫo da responsabilidade na execução do projeto condominial, 1957, São Paulo, Empresa Gráfica da Revista dos Tribunais Ltda., n.os 6-7, pp. 17/20.

12. C. c., art. 623, n. ${ }^{\circ} \mathrm{I}$.

13. C. c., arts. 488 e 634 .

14. C. p. c., arts. 302, n. ${ }^{\circ}$ VIII, 392,405 e 410 .

15. C. p. c., art. 90 . 
tigante, em se lhe deparando oportunidade de defender interêsses comuns a várias pessoas, se limite egoìsticamente à defesa dos interêsses próprios. É a consagração legal de que se dá a representação do litisconsorte inativo pelo litisconsorte ativo ${ }^{16}$.

Torna-se, assim, manifesto que os atos benéficos praticados por um condômino aproveitam aos demais. Seu exercício não impõe a unanimidade de apoio e nem reclama autorização prévia. Bem o observam Colin e Capitant: "De même, un copropriétaire n'a pas besoin de se ménager l'assentiment des autres pour apporter à la chose commune des modifications et des transformations, pourvu qu'elles ne causent aux autres consorts aucun préjudice et ne soient pas contraires à la destination de la chose" 17 .

Tem, pois, cada condômino o direito de agir em nome próprio, acarretando, com isso, proveito para os demais condôminos. E o direito de cada condômino é amplo como o do proprietário singular, limitado, apenas, pelo exercício de igual direito por parte de outro consorte. Expressiva e concludente é a lição, sempre nova, de Demolombe: "Nous croyons même que chacun des cohéritiers a également le droit, avant tout partage et durant l'indivision, d'agir, pour sa part, en revendication contre les tiers détenteurs des immeubles de l'hérédité, et plus généralement d'exercer, jusqu'à concurrence de sa part, toutes les actions dont le but sera de conserver son droit dans les biens héréditaires" 18 .

7. Se a administração do condomínio por planos cabe ao administrador, pelọ sistema legal regente (art. 8), assegurando-lhe, ainda, o diploma processual ação executiva, "para cobrar do co-proprietário do edifício de apartamentos

16. Pontes De MrRanda, Comentários ao código de processo civil, 1947, Rio de Janeiro, Rev. Forense, vol. 1, p. 347 e cit. Tratado de direito predial, vol. II, $\S 99$, p. 243.

17. Cours élémentaire de droit civil français, 1923, 4. ${ }^{\mathrm{a}}$ ed., Paris, Librairie Dalloz, vol. I, p. 777.

18. Cours de code de Napoléon, vol. $X V$, Traité des successions, 1859, Paris., L. Hachette et Cie., tomo III, n. ${ }^{\circ} 481$, p. 463. 
a quota relativa às despesas gerais fixadas em orçamento" 19 , seria desarrazoado negar-lhe o direito de representação para isto. Tanto mais quanto é princípio geral e indiscutível que, quem administra, tem representação judicial nos casos advindos de suas atribuições.

A qualificação do condomínio como ente coletivo, representado pelo administrador, nos limites estreitos da administração, encontra sustentáculos conhecidos.

Em sua monografia, Orlando Ribeiro Castro, levando ao extremo esta concepção, depois de enunciar que, "extinta a fase da incorporação, surgindo o condomínio por fórmulas jurídicas diversas como massa condômina, sociedade civil, sociedade por quotas ou anônimas, a critério do seu organizador", passa a desenvolver seu pensamento. Viu êle no próprio decreto (art. 9), em cuja análise se deteve, a criação de figura jurídica que, à míngua de denominação, chamou de massa condômina. E frisou: "o legislador criou uma figura jurídica, composta dos proprietários dos apartamentos, com atribuições definidas (deveres), podendo obrigar aos proprietários ao concurso nas despesas (direitos). Logo foi criada uma pessoa jurídica legal semelhante à massa falida na falência, a massa concorrente, no concurso de credores, ao espólio - no inventário, etc." ${ }^{20}$.

Embora essa construção seja extremada, encerrando confrontos nem sempre aceitáveis, proporciona subsídios para a representação orgânica.

Mais moderado num sentido, porém avançado em outro, é Carlos Maximiliano quando aceita a representação ativa e passiva do administrador em juízo, como se fora o "conjunto, em litígios contra o condomínio ou terceiros", para deduzir, ainda, que se não houver administrador "o

19. C. p. c., art. 298, alínea X.

20. Op. cit., pp. 28 e 63 . 
juiz designa um dos condôminos, para representar o todo, na lide contra êste iniciada" ${ }^{21}$.

Em têrmos de equilíbrio, entre estas duas opiniões, Eduardo Espinola, diz que "o administrador representa o condomínio em juízo, ativa e passivamente, dependendo em certos casos de poderes especiais" ${ }^{22}$.

8. Objetar-se-á, talvez, que no caso da ação executiva, atribuida ao administrador, tudo se passa no plano do fenômeno da substituição processual, em grau de singularidade, que não justificaria regra para representação orgânica do condomínio.

Essa figura do substituto processual, a bem dizer especiosa, idealizada na Alemanha, cuja conceituação e nomenclatura Chrovenda introduziu na ciência processual italiana, consiste no fenômeno pelo qual alguém age em nome próprio, mas no interêsse alheio.

Explica o laureado processualista, distinguindo a legitimatio ad causam da substituição processual, que muitas vêzes um direito, reconhecivel como pertencente a uma pessoa ou a uma entidade, faz-se valer em juízo por outra pessoa, mas em nome próprio, não como representante ${ }^{23}$.

9. Ocorre que várias das aplicações enumeradas pelo consagrado professor, como êle mesmo o reconhece ${ }^{24}$, são comumente explicadas como casos de representação.

Ademais, no código civil italiano de 1942, que disciplina a matéria "do condomínio nos edifícios" (livro III, tí-

21. Op. cit., n. ${ }^{\circ}$ 209, pp. 270/271. Diverge Pontes DE Miranda, situado entre os poucos que repulsam a representação judicial do administrador, argumentando que "a idéia da escolha de comuneiro que deva representar os demais é fora de qualquer fundamento jurídico. Nem há texto que pudesse invocar, nem princípio de direito. A representação só se dá em caso de revelia e por fôrça de lei processual, atendendo-se à unitariedade do litisconsórcio" (Cit. Tratado de direito predial, vol. $2, \S 99$, p. 244$)$.

22. Op. cit., n. ${ }^{\circ} 202$, p. 379 , nota 144.

23. Istituzioni di diritto processuale civile, $6 .^{\mathrm{a}}$ tiragem $\mathrm{da} 2 .^{\mathrm{a}} \mathrm{ed}$., 1957, Napoli, Casa Editrice dott. Eugenio Jovene, vol. I, n. ${ }^{\circ}$ 39, p. 157.

24. Op. cit., vol. II, $2 .^{\mathrm{a}}$ ed. revista, 1936, n. ${ }^{\circ} 223$, p. 229. 
tulo VII, capítulo II), ficou acolhido, expressamente, o princípio da representação, cometendo-se ao administrador, nos limites próprios de suas atribuições, agir em juízo seja contra os condôminos, seja contra terceiros ${ }^{25}$.

Alerta Giuseppe Branca que o fundamento dessa norma está em que o administrador representa ex necessario o condomínio. Há representação orgânica porque o condomínio é um ente coletivo e sua vontade se manifesta através da pessoa do órgão, o administrador. Dentre as atribuições conferidas ao administrador, "che parla ex necessario la voce del gruppo", figuram as de agir em juizo "a nome del condominio, per le stesse cause per cui agisce contro i tezi. E, questo, un ulteriore riflesso della sua qualità di organo dell'ente: egli tutela l'interesse del gruppo (e non solo quello dei singoli condomini) anche contro i suoi stessi componenti" ${ }^{26}$.

Elucidam outros que, ao se reproduzir a disposição do art. 20 do Real decreto lei de 15 de janeiro de 1934, relativamente à representação dos condôminos, ocorreu conversão da fórmula, ampliando-se, assim, o âmbito dessa re-

25. O art. 1131 do c.c. italiano, sob a epígrafe "rappresentanza" dispõe: “Nei limiti delle attribuzioni stabilite dall'articolo precedente o dei maggiori poteri conferitigli dal regolamento di condominio (1135) o dall'assemblea, l'amministratore ha la rappresentanza dei partecipanti e può agire in giudizio sia contro $\mathrm{i}$ condomini sia contro $\mathrm{i}$ terzi (1133).

Può essere convenuto in giudizio per qualunque azione concernente le parti comuni (1117) dell'edificio; a rul sono notificati i provvedimenti dell'autorità amministrativa che si riferiscono allo stesso oggetto (Att. 65).

Qualora la citazione o il provvedimento abbia un contenuto che esorbita dalle attribuzioni dell'amministratore, questi è tenuto a darne senza indugio notizia all'assemblea dei condomini.

L'amministratore che non adempie a quest'obbligo può essere revocato (1129) ed è tenuto al risarcimento dei danni (1138; Att. 64).

26. Della proprietà, in Commentário del codice civile, a cargo deAntonio Scialoja, 1951, Bolonha - Roma, S. I. A. E., pp. 406 e 433/436. 
presentação concedida ao administrador "nelle liti promosse contro i partecipanti" ${ }^{27}$

10. Já parece equacionado, tanto como problema quanto como conceito, que a representação orgânica do condomínio, em esfera circunscrita, constitui imperativo no direito moderno.

Basta discernir, quer na representação ativa, quer na passiva, aquilo que se contém nas atribuições inerentes ao administrador e aquilo que encerra os direitos dos próprios condôminos, não envolvendo interêsses da comunhão.

Assim distinguido, sob o prisma ativo tem o administrador representação para agir contra o condômino ou qualquer estranho em tudo quanto resulte de suas atribuições normais. Cabe-lhe, independentemente de autorização da assembléia, cobrar em juízo, do condômino faltoso, sua quota relativa às despesas gerais fixadas em orçamento; obstar, mediante medida judicial, que se estabeleçam no apartamento - desnaturando-se sua finalidade residencial - enfermarias, oficinas, laboratórios ou instalações perigosas; impedir que o condômino transmude em uso privado as partes de uso comum do edifício, como os corredores, caminhos internos, entradas principal e de serviço; opôr-se à mudança da forma externa da fachada do prédio ou à alteração das esquadrias externas e tantas outras medidas - inclusive as possessórias sôbre as áreas e coisas comuns -- que muitás leis regentes do condomínio especificam ${ }^{28}$.

Tem o administrador, por outro lado, a representação passiva do condomínio, em qualquer processo em que se

27. G. Pandolfelli, G. Scarpelo, M. Stellla Richter, G. Dallar, Codice civile, 1941, Milano, Dott. A. Giuffrè, p. 285; Nicola STrolfi e Francesco Stolfi, Il nuovo codice civile comentato, 1944, Napoli, Casa Editrici Dott. Eugenio Jovene, vol. III, p. 437.

28. Entre nós, o cit. dec. 5.481, de 25.6.1928, no seu art. 11, veda ao proprietário de apartamento uma série dêsses atos, permitindo que o "interessado" intente a competente ação, o que não exclui, antes justifica, o ingresso do administrador em juízo, pois seu interêsse nisso a benefício do condomínio e bom desempenho da administração, não pode ser menor. 
litigue a respeito das deliberações tomadas em assembléia, envolventes de direitos de terceiros, condôminos ou não; nas reclamações trabalhistas; nas ações possessórias e petitórias relativas às partes comuns e em outras oportunidades mais. Não na tem, por óbvio, estando em jôgo direitos exclusivos dos condôminos, verbi gratia, na desapropriação.

A expropriação - ensina CunHa Gonçalves - "ainda que parcial, deverá ser feita com citação de todos os proprietários; e a respectiva indenização paga pela entidade expropriante deverá ser rateada entre todos os condôminos, proporcionalmente ao valor dos seus apartamentos. Se, porém, a expropriação fôr parcial e a parte expropriada pertencer, apenas, a um grupo de condôminos, é claro que só êstes poderão participar do rateio da referida indenização" ${ }^{29}$.

Teve Carlos Maximiliano a intuição do problema ao notar, com arrimosi em Visco e PeretTi Griva, que o administrador, nos limites da lei e do regulamento ou título do imóvel, "representa em juízo o conjunto, em litígios contra condômino ou terceiro, como autor ou réu". Prossegue afirmando que o administrador "pode agir no fôro, por alvedrio próprio, nos casos inerentes ao seu cargo: por exemplo, nas controvérsias relativas a deliberações da assembléia de consortes, cobrança das quotas dos co-interessados, locação de coisa comum ou licenciamento do porteiro. Propõe ações possessórias, de nunciação de obra nova e dano temido, sequestros e outros atos conservatórios e ur-

29. Cit. Da propriedade horizontal ou por andares, n. ${ }^{\circ} 15$, pp. 66 /67. Dispõe o art. 7, parágrafo único do cit. dec. 5.481, de 25.6.1928, que a desapropriação "alcançará sempre a totalidade do edifício com tôdas as suas dependências", estabelecendo, assim, restrição até antieconômica para o poder expropriante e instituindo regra de duvidoso caráter absoluto.

Observa Pontes De Miranda, a propósito dessa limitação, que "isso não quer dizer que se não possa desapropriar apenas um pedaço de terreno não construído", pois a "lei fala da totalidade do edifício, e não de totalidade do prédio" (Op. vol. cits., § 104, p. 253). 
gentes, bem como ações petitórias com objeto reintegrativo; enfim, tudo o que tenha caráter e finalidade de conservação". Finaliza frisando que "maiores são os poderes do síndico em hipótese de representação passiva, quando a comunidade seja Ré. Se êle não dá conta, aos condôminos, da citação recebida, nem por isto a mesma e as respectivas conseqüências deixam de atingir a todos; pois a obrigação de comunicar é interna" 30

11. A conclusão que se impõe, se não falhou a econômia dêste estudo, é a de que, embora o condomínio não seja pessoa jurídica ${ }^{31}$, traduz conjunto econômico-juridico que enseja representação. Tal representação, naquilo que não discrepa da configuração unitária e dentro das lindes anteriormente distinguidas, deve caber ao administrador como intérprete legítimo da voz do órgão.

30. Op. cit., n. ${ }^{\circ} 209$. pp. $270 / 271$.

31. Carlos maximiliano, op. cit., n. ${ }^{\circ}$ 205, p. 267; Calogero Gangi, Persone fisiche e persone giuridiche, 1948, Milano, Dott. A. Giuffrè, n. ${ }^{\circ}$ 171, pp. 223/224; ANTONIO VISco, La disciplina giuridica delle case in condominio, $4^{\mathrm{a}}$ ed., 1953, Milano, Dott. A. Giuffrè, n.o 156, p. 238. 